\title{
Association of axillary node status with clinicopathological characteristics and expression of EZH2 and CD44 in primary breast ductal carcinoma
}

\author{
Miodrag Djordjevic ${ }^{1}$, Aleksandar Karanikolic ${ }^{2}$, \\ Ljubinka Velickovic ${ }^{3}$, Maja Milentijevic ${ }^{4}$
}

\begin{abstract}
Objective: In order to enhance the prognostic benefit of new molecular markers, the aim of this study was to identify possible association of axillary lymph node (ALN) status and $\mathrm{pN}$ with clinicopathological characteristics and expression of EZH2 and CD44 in invasive ductal carcinoma (IDC) of the breast.

Methods: The investigation included 106 patients with IDC who had undergone radical mastectomy at the Clinic of Endocrine Surgery in Nis. Clinicopathologic parameters and immunohistochemical expression of EZH2 and CD44 in primary IDC were investigated in relation to ALN status and pN.

Results: Our univariate analysis established that T3-T4 stage, high EZH2, and high EZH2 with ER- were associated with ALN metastasis $(p=0.014 ; 0.003 ; 0.013)$. Decreased probability for ALN involvement was found with T1 stage, and low EZH2 with $E R+(p=0.032 ; 0.022)$. Multivariant analysis established that high EZH2 in cancer cells was associated with high risk for ALN metastases $(p=0.004)$; T1 tumors were associated with low risk $(\mathrm{p}=0.037)$. Higher $\mathrm{pN}$ was associated with high $\mathrm{EZH} 2$, high $\mathrm{EZH} 2$ with $\mathrm{ER}-$, as well as an advanced clinical and disease stage $(p=0.006 ; 0.001 ; p=0.002,0.001)$. Lower $p N$ was associated with $E R+$, and ER+ with low EZH2 ( $p=0.004 ; 0.012)$. CD44 was not associated with ALN involvement, nor with $p N$.

Conclusions: This study revealed association of EZH2 with ALN metastases, where disease stage and expression profiles of EZH2 and ER may have affected regional $\mathrm{pN}$.
\end{abstract}

KEYWORDS: Axillary node status, pN, EZH2, CD44, Breast cancer.

doi: https://doi.org/10.12669/pjms.36.7.2954

How to cite this:

Djordjevic M, Karanikolic A, Velickovic L, Milentijevic M. Association of axillary node status with clinicopathological characteristics and expression of EZH2 and CD44 in primary breast ductal carcinoma. Pak J Med Sci. 2020;36(7):1539-1544. doi: https://doi.org/10.12669/pjms.36.7.2954

This is an Open Access article distributed under the terms of the Creative Commons Attribution License (http://creativecommons.org/licenses/by/3.0), which permits unrestricted use, distribution, and reproduction in any medium, provided the original work is properly cited.

1. Miodrag Djordjevic,

Clinic of Endocrine Surgery, Nis, Serbia.

2. Aleksandar Karanikolic,

Clinic of Endocrine Surgery, Nis, Serbia.

3. Ljubinka Velickovic,

Institute of Pathology, Nis, Serbia.

4. Maja Milentijevic,

Institute of Pathology, Nis, Serbia.

1-4: Medical Faculty, University Nis,

Serbia.

Correspondence:

Dr. Miodrag Djordjevic,

Clinic of Endocrine Surgery, Nis, Serbia.

Medical Faculty, University Nis,

Serbia.

Email: mija.djordjevic@yahoo.com

* Received for Publication:

May 24, 2020

* Revision Received:

* Revision Accepted: *

July 22, 2020

August 18, 2020

\section{INTRODUCTION}

Breast cancer $(\mathrm{BC})$ is the most diagnosed type of cancer in women throughout the world, and it has the second highest mortality rate in this group, after lung cancer. ${ }^{1-3}$ Invasive carcinoma of no special type (ductal NOS) is the most common histologic type of invasive BC, comprising $75 \%$ to $80 \%$ of newly diagnosed invasive tumors. ${ }^{2}$ Earlier diagnosis and improved treatment modalities of $\mathrm{BC}$ in the last several decades have led to the 5-year survival rates of $\mathrm{BC}$ patients to be raised to about $85 \%$. Nevertheless, local and distant metastases still tend to occur and contribute to a poor prognosis of the disease. ${ }^{4}$ Presence of axillary lymph node 
(ALN) metastases is the most important prognostic factor for disease free and overall survival in the absence of distant metastasis and it is important for determining treatment. ${ }^{5}$

Expression profiles of hormone receptors (ER, PR), and Her-2/neu are closely associated with BC, being therefore used for prognosis and therapeutic response predictions. ${ }^{4}$ Some studies have shown that along with these parameters, Enhancer of Zeste Homolog 2 (EZH2) and CD44, molecular markers with cancer stem characteristics, have an important role in the prognosis of $\mathrm{BC} .{ }^{6} \mathrm{EZH} 2$ is the catalytic subunit of Polycomb repressive complex 2 (PRC2), which is a highly conserved histone methyltransferase that targets lysine- 27 of histone H3. Studies on human tumors show that EZH2 is frequently over-expressed in a wide variety of cancerous tissue types, including BC, where is consistently associated with poor prognosis and aggressive behavior, including invasiveness and metastatic potential. ${ }^{7-9}$ EZH2 promotes BC progression by transcriptional repression of tumor suppressors and by maintaining the cells in a stem cells state. ${ }^{7}$ CD44 is a well-known marker with a role in promoting tumorigenesis of $\mathrm{BC}$, including transformation, growth, cell invasion and motility, and is a marker of BC stem cells. ${ }^{7}$ In order to enhance the prognostic benefit of standard and new molecular markers on the occurrence of metastases in $\mathrm{BC}$, the expression of $\mathrm{EZH} 2$ and CD44 was examined.

In order to enhance the prognostic benefit of new molecular markers, the aim of this study was to identify possible association of axillary lymph node (ALN) status and $\mathrm{pN}$ with clinicopathological characteristics and expression of EZH2 and CD44 in invasive ductal carcinoma (IDC) of the breast.

\section{METHODS}

This study included one hundred six patients with invasive breast ductal carcinoma (IDC) who had undergone a radical mastectomy at Clinic of Endocrine Surgery, Clinical Center Nis, Serbia, between January 2016 and December 2019. It excluded the patients who received neoadjuvant therapy before surgery. Clinicopathologic parameters - patient age, pT (T1, T2, T3-T4), ALN metastasis (yes or no), pN (N0, N1, N2-3), clinical stage, grade of tumor $(1,2,3)$, Nottingham score, ER/HER-2 status (negative, positive), Ki-67 index (low $<20 \%$, high $\geq 20 \%$ ), and expression of EZH2 and CD44 were included in this study.
We performed immunohistochemistry on thin sections $(4 \mu \mathrm{m})$ of tissue slides to examine the expression of EZH2 (clone ab84989, Abcam, 1/250 dilution), and CD44 (Dako, 1:50 dilution). The sections were cut, dried, deparaffinized, rehydrated, heat-pretreated using retrieval solution and stained with antibodies following standard procedures. Visible brown nuclear staining, predominantly moderate, was considered to indicate positive staining for EZH2, and membranous for CD44. The staining intensity was scored from 0 to 3 (no staining, weak, moderate, strong). The proportions of stained positive tumor cells were classified as $1(0-25 \%), 2$ (26-50\%), $3(51-75 \%)$ and 4 (76-100\%). Multiplication for intensity and proportion was utilized to represent the protein levels of EZH2 and CD44. Based on the mean score for the entire study group, EZH2 expression in tumors was categorized into low and high expression groups. CD44 expression was scored as low, if $\leq 50 \%$ of cells were stained; and high, if $>51 \%$ of cells were stained. ${ }^{8-10}$

Pearson chi-square test was used to assess the differences in distribution of investigated parameters among the patients with negative and positive ALN involvement and pN.The relationship between each investigated parameters and the risk of ALN metastasis was assessed using univariate logistic regression. Odds ratios (ORs) and their corresponding 95\% confidence intervals (95\% CIs) were calculated. We used backward LR method, which involves starting with all examined variables, to select variables that should be included in final multivariate regression model.

The tests were all two-sided and analyzed using the SPSS software package, version 18.0 (SPSS Inc., Chicago, IL, USA). The value of $\mathrm{P}<0.05$ was considered statistically significant.

\section{RESULTS}

During the study period, 106 women underwent radical mastectomy because of IDC, and they did not have distant disease. Most of the studied patients $(89.6 \%)$ were over 45 years of age. ALN metastases were detected in $60.4 \%$ women. Investigation of relationships between ALN status and investigated parameters showed that ALN metastases were closely linked to tumor stage $(\mathrm{p}=0.012)$, clinical stage $(p=0.019)$ and expression of EZH2 $(p=0.003)$. Low expression of CD44 was detected in $67 \%$ patients, and significant association with ALN status and $\mathrm{pN}$ was not detected (Table-I). In the univariate logistic regression analysis, T3-T4 tumor stage 
Table-I: Association of lymph node involvement with clinicopathological characteristics and expression ofEZH2 and CD44 in primary IDC.

\begin{tabular}{|c|c|c|c|c|}
\hline \multirow[t]{2}{*}{ Parameter } & \multirow[t]{2}{*}{ No. of patients } & \multicolumn{2}{|c|}{ Lymph nodes involvement } & \multirow[t]{2}{*}{ P Value } \\
\hline & & Negative & Positive & \\
\hline \multicolumn{5}{|l|}{ Age, years } \\
\hline$\leq 45$ godina & $11(10.4 \%)$ & $3(7.1 \%)$ & $8(12.5 \%)$ & 0.376 \\
\hline$>45$ godina & $95(89.6 \%)$ & $39(92.9 \%)$ & $56(87.5 \%)$ & \\
\hline \multicolumn{5}{|l|}{ Grade } \\
\hline G1 & $6(5.7 \%)$ & $3(7.1 \%)$ & $3(4.7 \%)$ & 0.867 \\
\hline G2 & $64(60.4 \%)$ & $25(59.5 \%)$ & $39(60.9 \%)$ & \\
\hline G3 & $36(34 \%)$ & $14(33.3 \%)$ & $22(34.4 \%)$ & \\
\hline Nottingham score & $6.85 \pm 1.18$ & $6.93 \pm 1.02$ & $6.81 \pm 1.30$ & 0.626 \\
\hline \multicolumn{5}{|c|}{ Pathologic stage, no.(\%) } \\
\hline $\mathrm{T} 1$ & $35(33 \%)$ & $19(45.2 \%)$ & $16(25 \%)$ & 0.012 \\
\hline $\mathrm{T} 2$ & $50(47.2 \%)$ & $20(47.6 \%)$ & $30(46.9 \%)$ & \\
\hline $\mathrm{T} 3$ - T4 & $21(19.8 \%)$ & $3(7.1 \%)$ & $18(28.1 \%)$ & \\
\hline \multicolumn{5}{|l|}{$p N$, no. $(\%)$} \\
\hline N0 & $42(39.6 \%)$ & $42(100 \%)$ & $0(0 \%)$ & \\
\hline N1 & $36(34 \%)$ & $0(0 \%)$ & $36(56.3 \%)$ & 0.000 \\
\hline N2-N3 & $28(26.4 \%)$ & $0(0 \%)$ & $28(43.7 \%)$ & \\
\hline \multicolumn{5}{|c|}{ Clinical stage, no.(\%) } \\
\hline I & $24(21.6 \%)$ & $19(45.2 \%)$ & $5(7.8 \%)$ & \\
\hline II & $59(55.7 \%)$ & $21(50.1 \%)$ & $38(59.4 \%)$ & 0.019 \\
\hline III & $23(22.7 \%)$ & $2(4.7 \%)$ & $21(32.8 \%)$ & \\
\hline \multicolumn{5}{|l|}{ ER status } \\
\hline Negative, no.(\%) & $55(51.9 \%)$ & $19(45.2 \%)$ & $36(56.3 \%)$ & 0.267 \\
\hline Positive, no. $(\%)$ & $51(48.1 \%)$ & $23(54.8 \%)$ & $28(43.7 \%)$ & \\
\hline \multicolumn{5}{|l|}{ HER-2/neu status } \\
\hline Negative, no.(\%) & $76(71.7 \%)$ & $31(73.8 \%)$ & $45(70.3 \%)$ & 0.696 \\
\hline Positive, no. $(\%)$ & $30(28.3 \%)$ & $11(26.2 \%)$ & $19(29.7 \%)$ & \\
\hline \multicolumn{5}{|l|}{ Ki-67 index } \\
\hline Low $(<20)$ & $35(33 \%)$ & $11(26.2 \%)$ & $24(37.5 \%)$ & \\
\hline High $(\geq 20)$ & $71(67 \%)$ & $31(73.8 \%)$ & $40(62.5 \%)$ & 0.672 \\
\hline \multicolumn{5}{|l|}{ CD44 no.(\%) } \\
\hline Low & $71(67 \%)$ & $30(71.4 \%)$ & $41(64.1 \%)$ & 0.430 \\
\hline High & $35(33 \%)$ & $12(28.6 \%)$ & $23(35.9 \%)$ & \\
\hline \multicolumn{5}{|l|}{ EZH2 no.(\%) } \\
\hline Low & $54(50.9 \%)$ & $29(69 \%)$ & $25(39.1 \%)$ & 0.003 \\
\hline High & $52(49.1 \%)$ & $13(31 \%)$ & $39(60.9 \%)$ & \\
\hline
\end{tabular}

$(\mathrm{OR}=5.087 ; 95 \% \mathrm{CI}: 1.394-18.654 ; \mathrm{p}=0.014)$, clinical stage III (OR=5.018; 95\%CI: 1.941-17.156; $\mathrm{p}=0.018)$, high EZH2 (OR=3.480; 95\%CI: 1.526-7.939; $\mathrm{p}=0.003)$, and high EZH2 with negative ER status (OR=4.318; 95\%CI: 1.356-13.746; $p=0.013$ ) were found to increase the probability for ALN involvement, while T1 tumor stage (OR=0.404; 95\%CI: 0.176$0.926 ; \mathrm{p}=0.032)$, clinical stage I $(\mathrm{OR}=0.420 ; 95 \% \mathrm{CI}$ : $0.206-0.905 ; \mathrm{p}=0.039)$ and low EZH2 with positive ER status (OR=0.327; 95\%CI: 0.126-0.849; $\mathrm{p}=0.022)$ were associated with decreased probability for ALN involvement (Table-II). In the multivariate logistic regression model, $\mathrm{T} 1$ tumor stage $(\mathrm{OR}=0.393 ; 95 \% \mathrm{CI}$ : $0.163-0.946 ; \mathrm{p}=0.037)$ and high EZH2 (OR=3.479; 95\%CI: 1.491-8.116; $\mathrm{p}=0.004)$ remained significantly associated with ALN status (Table-II).

The cancer spread to $1-3$, or $\geq 4$ axillary lymph nodes in $34 \%$, ie. $26.4 \%$ patients. The higher $\mathrm{pN}$ was closely linked to tumors stage $(p<0.001)$, clinical stage $(p=0.002)$, high EZH2 $(p=0.006)$ and high EZH2 with negative ER status $(p<0.001)$. Lower $\mathrm{pN}$ was associated with positive ER status $(\mathrm{p}=0.004)$, as well aslow EZH2 with positive ER status $(\mathrm{p}=0.012)($ Table-III). 
Table-II: Logistic regression analysis of clinicopathological characteristics, expression of EZH2 and CD44 and lymph node involvementinprimary IDC.

\begin{tabular}{|c|c|c|c|c|}
\hline \multirow[t]{2}{*}{ Parameter } & \multirow[t]{2}{*}{ OR } & \multicolumn{2}{|c|}{ 95\% C.I. } & \multirow[t]{2}{*}{ P value } \\
\hline & & Lower & Upper & \\
\hline \multicolumn{5}{|c|}{ Univariate analysis } \\
\hline Age $>45$ years & 0.538 & 0.134 & 2.158 & 0.382 \\
\hline G1 & 0.639 & 0.123 & 3.329 & 0.595 \\
\hline G2 & 1.061 & 0.479 & 2.349 & 0.884 \\
\hline G3 & 1.048 & 0.460 & 2.386 & 0.912 \\
\hline Stage I & 0.420 & 0.206 & 0.905 & 0.039 \\
\hline Stage II & 0.943 & 0.465 & 2.012 & 0.940 \\
\hline Stage III & 5.018 & 1.941 & 17.156 & 0.018 \\
\hline Nottinghem score & 0.920 & 0.661 & 1.281 & 0.622 \\
\hline $\mathrm{T} 1$ & 0.404 & 0.176 & 0.926 & 0.032 \\
\hline $\mathrm{T} 2$ & 0.971 & 0.445 & 2.116 & 0.940 \\
\hline $\mathrm{T} 3$ - T4 & 5.087 & 1.394 & 18.564 & 0.014 \\
\hline ER status positive & 0.643 & 0.294 & 1.406 & 0.268 \\
\hline $\begin{array}{l}\text { HER-2/neu } \\
\text { status positive }\end{array}$ & 1.190 & 0.497 & 2.846 & 0.696 \\
\hline High Ki-67 index & 0.591 & 0.252 & 1.389 & 0.228 \\
\hline High EZH2 & 3.480 & 1.526 & 7.939 & 0.003 \\
\hline High CD44 & 1.402 & 0.604 & 3.255 & 0.431 \\
\hline $\begin{array}{l}\text { High EZH2 } \\
\text { and High CD44 }\end{array}$ & 1.057 & 0.321 & 3.482 & 0.927 \\
\hline $\begin{array}{l}\text { Low EZH2 } \\
\text { and Low CD44 }\end{array}$ & 0.603 & 0.275 & 1.321 & 0.206 \\
\hline $\begin{array}{l}\text { High EZH2 } \\
\text { and Low CD44 }\end{array}$ & 2.442 & 0.931 & 6.408 & 0.070 \\
\hline $\begin{array}{l}\text { Low EZH2 } \\
\text { and High CD44 }\end{array}$ & 0.714 & 0.238 & 2.143 & 0.548 \\
\hline $\begin{array}{l}\text { High EZH2 } \\
\text { and ER positive }\end{array}$ & 1.548 & 0.622 & 3.852 & 0.347 \\
\hline $\begin{array}{l}\text { Low EZH2 } \\
\text { and ER negative }\end{array}$ & 0.600 & 0.257 & 1.400 & 0.238 \\
\hline $\begin{array}{l}\text { High EZH2 } \\
\text { andER negative }\end{array}$ & 4.318 & 1.356 & 13.746 & 0.013 \\
\hline $\begin{array}{l}\text { Low EZH2 } \\
\text { and ER positive }\end{array}$ & 0.327 & 0.126 & 0.849 & 0.022 \\
\hline \multicolumn{5}{|c|}{ Multivariate analysis } \\
\hline $\mathrm{T} 1$ & 0.393 & 0.163 & 0.946 & 0.037 \\
\hline High EZH2 & 3.479 & 1.491 & 8.116 & 0.004 \\
\hline
\end{tabular}

ALN status remains one of the fundamental prognostic factors in BC and the TNM classification system remains the gold standard for staging the disease. ALN status has been used for guiding adjuvant, local or systemic treatment decisions.,11 Wasuthit et al. suggested a combination of clinical, radiologic, and pathologic characteristics for the prediction of ALN involvement and selection of BC patients for full ALN dissection. ${ }^{12}$

$\mathrm{EZH} 2$ is essential in a number of important cellular processes, such as embryonic and adult stem cell maintenance and tumor progression. ${ }^{13}$ Depletion of EZH2 in BC cells significantly increased expression of the top altered genes, decreased proliferation, and improved cell adhesion, indicating a critical role played by EZH2 in determining the cancer phenotype. ${ }^{14}$

Having in the mind that a key event in the progression of $\mathrm{BC}$ is the development of lymph node metastases, it is very important to determine prognostic benefit of standard and new molecular markers (ER, HER2, EZH2, CD44) on the occurrence of metastatic disease. This study detected that patients with advanced tumor stage, high EZH2, and high EZH2 with negative ER status had a high risk for ALN metastases in the univariate analysis ( $p=0.014 ; 0.003 ; 0.013)$. Low risk for ALN involvement was detected in patients with T1 stage, and tumors with positive ER status and low EZH2 ( $p=0.032 ; 0.022)$. Multivariate analysis detected that ALN metastases were significantly associated with high expression of EZH2 in cancer cells $(p=0.004)$, and T1 stage had a low risk for ALN involvement ( $\mathrm{p}=0.037)$.

Our results are consistent with the studies of some other authors who detected that overexpression of EZH2 was associated with larger tumor size, advanced disease, and significantly worse disease free and overall survival than those with tumors expressing low EZH2, but added that overexpression of EZH2 was associated with negative ER status. ${ }^{15,16}$ Reijm et al. showed that high EZH2 expression was associated with the lymph node status only in univariate analysis. They found significant positive associations with the number of lymph nodes involved, histologic grade and HER2 status. ${ }^{17}$

Biological evidence has shown that overexpression of EZH2 induces type 1 histone deacetylation (HDAC) enzymatic activity in breast epithelial cells. Furthermore, the HDAC activity induced by EZH2 may explain the strong association between EZH2 protein expression and negative ER, showing that EZH2 may transcriptionally repress ER. ${ }^{18,19}$

Recent findings of Yomtoubian et al. showed that specific pharmacological or genetic inhibition of EZH2 catalytic activity impairs distant metastasis in triple negative breast cancer patients. EZH2 inhibition differentiates EZH2 high basal cells to a luminal-like phenotype by derepressing GATA3 and renders them sensitive to endocrine therapy. ${ }^{20}$ Polycomb inhibitors, especially those directed 
Table-III: Association of $\mathrm{pN}$ with clinicopathological characteristics and expression ofEZH2 and CD44 in primary IDC.

\begin{tabular}{|c|c|c|c|c|}
\hline \multirow[t]{2}{*}{ Parameter } & \multicolumn{3}{|c|}{$p N$} & \multirow[t]{2}{*}{ P Value } \\
\hline & NO & N1 & $N 2-N 3$ & \\
\hline \multicolumn{5}{|l|}{ Age, years } \\
\hline$\leq 45$ godina & $3(7.1 \%)$ & $5(13.9 \%)$ & $3(10.7 \%)$ & \multirow{2}{*}{0.621} \\
\hline$>45$ godina & $39(92.9 \%)$ & $31(86.1 \%)$ & $25(89.3 \%)$ & \\
\hline \multicolumn{5}{|l|}{ Grade } \\
\hline G1 & $3(7.1 \%)$ & $3(8.3 \%)$ & $0(0.0 \%)$ & \multirow[t]{3}{*}{0.053} \\
\hline G2 & $25(59.5 \%)$ & $26(72.2 \%)$ & $13(46.4 \%)$ & \\
\hline G3 & $14(33.3 \%)$ & $7(19.4 \%)$ & $15(53.6 \%)$ & \\
\hline Nottingham score & $6.93 \pm 1.02$ & $6.42 \pm 1.18$ & $7.32 \pm 1.28$ & 0.160 \\
\hline \multicolumn{5}{|l|}{ Pathologic stage, no.(\%) } \\
\hline $\mathrm{T} 1$ & $19(45.2 \%)$ & $11(30.6 \%)$ & $5(17.9 \%)$ & \multirow[t]{3}{*}{0.000} \\
\hline $\mathrm{T} 2$ & $20(47.6 \%)$ & $23(63.9 \%)$ & $7(25.0 \%)$ & \\
\hline $\mathrm{T} 3-4$ & $3(7.1 \%)$ & $2(5.5 \%)$ & $16(57.1 \%)$ & \\
\hline \multicolumn{5}{|l|}{ Clinical stage, no.(\%) } \\
\hline I & $19(45.2 \%)$ & $5(10.6 \%)$ & $0(0.0 \%)$ & \multirow{3}{*}{0.002} \\
\hline II & $21(50.1 \%)$ & $38(80.9 \%)$ & $0(0.0 \%)$ & \\
\hline III & $2(4.7 \%)$ & $4(8.5 \%)$ & $17(100 \%)$ & \\
\hline \multicolumn{5}{|l|}{ ER status } \\
\hline Negative, no.(\%) & $19(45.2 \%)$ & $14(38.9 \%)$ & $22(78.6 \%)$ & \multirow[t]{2}{*}{0.004} \\
\hline Positive, no. $(\%)$ & $23(54.8 \%)$ & $22(61.1 \%)$ & $6(21.4 \%)$ & \\
\hline \multicolumn{5}{|l|}{ HER-2/neu status } \\
\hline Negative, no.(\%) & $31(73.8 \%)$ & $27(75.0 \%)$ & $18(64.3 \%)$ & \multirow[t]{2}{*}{0.593} \\
\hline Positive, no. $(\%)$ & $11(26.2 \%)$ & $9(25.0 \%)$ & $10(35.7 \%)$ & \\
\hline \multicolumn{5}{|l|}{ Ki-67 index } \\
\hline Low $(<20)$ & $11(26.2 \%)$ & $19(52.8 \%)$ & $5(17.9 \%)$ & \multirow[t]{2}{*}{0.060} \\
\hline $\operatorname{High}(\geq 20)$ & $31(73.8 \%)$ & $17(47.2 \%)$ & $23(82.1 \%)$ & \\
\hline \multicolumn{5}{|l|}{ CD44 no.(\%) } \\
\hline Low & $30(71.4 \%)$ & $23(63.9 \%)$ & $18(64.3 \%)$ & \multirow[t]{2}{*}{0.732} \\
\hline High & $12(28.6 \%)$ & $13(36.1 \%)$ & $10(35.7 \%)$ & \\
\hline \multicolumn{5}{|l|}{ EZH2 nо.(\%) } \\
\hline Low & $29(69.0 \%)$ & $16(44.4 \%)$ & $9(32.1 \%)$ & \multirow[t]{2}{*}{0.006} \\
\hline High & $13(31.0 \%)$ & $20(55.6 \%)$ & $19(67.9 \%)$ & \\
\hline High EZH2 and High CD44 & $5(11.9 \%)$ & $2(5.6 \%)$ & $6(21.4 \%)$ & 0.158 \\
\hline Low EZH2 and Low CD44 & $23(54.8 \%)$ & $17(47.2 \%)$ & $10(35.7 \%)$ & 0.294 \\
\hline High EZH2 and Low CD44 & $7(16.7 \%)$ & $13(36.1 \%)$ & $8(28.6 \%)$ & 0.145 \\
\hline Low EZH2 and High CD44 & $7(16.7 \%)$ & $4(11.1 \%)$ & $4(14.3 \%)$ & 0.782 \\
\hline High EZH2 and ER positive & $9(21.4 \%)$ & $14(38.9 \%)$ & $5(17.9 \%)$ & 0.107 \\
\hline Low EZH2 and ER negative & $15(35.7 \%)$ & $8(22.2 \%)$ & $8(28.6 \%)$ & 0.425 \\
\hline High EZH2 and ERnegative & $4(9.5 \%)$ & $6(16.7 \%)$ & $14(50.0 \%)$ & 0.000 \\
\hline Low EZH2 and ER positive & $14(33.3 \%)$ & $8(22.2 \%)$ & $1(3.6 \%)$ & 0.012 \\
\hline
\end{tabular}

against the PRC2 catalytic subunit EZH2 have shown responses in preclinical studies of cancer therapy. ${ }^{9}$

The number of lymph nodes involved has emerged as a prognostic factor in determining BC prognosis. Patients with four or more positive lymph nodes have a worse prognosis compared to those having three or fewer histologically positive lymph nodes. ${ }^{21}$ This study identified that higher $\mathrm{pN}$ was associated with some parameters which influenced ALN involvement, i.e. with high EZH2, high EZH2 with negative ER status, advanced clinical stage and advanced tumors stage $(\mathrm{p}=0.006 ; 0.001 ; \mathrm{p}=0.002$; 0.001). Patients with pN2-N3 had high EZH2 in $67.9 \%$, and high EZH2 with negative ER status was seen in $50 \%$. However, lower $\mathrm{pN}$ can be expected in women with positive ER status separately $(\mathrm{p}=0.004)$ or together with low EZH2 expression $(p=0.012)$. Despite the strong association of EZH2 with ALN status, our study has some limitations having in the mind that it was done in one center.

Some studies indicate that multifunctional cell adhesion molecules CD44 are potential markers of tumour progression, and may favor distant 
metastasis. ${ }^{22}$ This study investigated the expression of CD44 to clarify its impact on ALN status and pN. Low CD44 was present in $67 \%$ of IDC. A high EZH2 expression with CD44 reduction in cancer cells had a certain impact on ALN involvement (OR $2.442,95 \%$ CI 0.931-6.408, $\mathrm{p}=0.070)$, but a significant association was not detected.

\section{CONCLUSION}

Despite some limitations, (the study has been conducted on the sample size from only one center) this study points the association of high EZH2 expression in IDBC with ALN metastases, where increasing $\mathrm{pN}$ was associated with more advanced tumor and clinical stage, high EZH2, and high EZH2 with negative ER status. Our study showed that EZH2 and ER can facilitate regional lymph node metastatic progression in women with BC.

\section{Grant Support E Financial Disclosures: None.}

\section{REFERENCES}

1. Majeed AI, Ullah A, Jadoon M, Ahmad W, Riazuddin S. Screening, diagnosis and genetic study of breast cancer patients in Pakistan. Pak J Med Sci. 2020;36(2):16-20. doi: 10.12669/ pims.36.2.1059

2. Spronk I, Schellevis FG, Burgers JS, de Bock GH, Korevaar JC. Incidence of isolated local breast cancer recurrence and contralateral breast cancer: A systematic review. Breast. 2018;39:70-79. doi: 10.1016/j.breast.2018.03.011

3. Siegel RL, Miller KD, Jemal A. Cancer statistics, 2018. CA Cancer J Clin. 2018;68:7-30. doi: 10.3322/caac.21442

4. Chen L, Linden HM, Anderson BO, Li CI. Trends in 5-year survival rates among breast cancer patients by hormone receptor status and stage. Breast Cancer Res Treat. 2014;147(3):609-616. doi: 10.1007/s10549-014-3112-6

5. Verheuvel NC, Ooms HW, Tjan-Heijnen VC, Roumen RM, Voogd AC. Predictors for extensive nodal involvement in breast cancer patients with axillary lymph node metastases. Breast. 2016;27:175-181. doi: 10.1007/s10549-017-4342-1

6. Saeg F, Anbalagan M. Breast cancer stem cells and the challenges of eradication: a review of novel therapies. Stem Cell Investig. 2018;5:39. doi: 10.21037/sci.2018.10.05.

7. Hitoshi I, Nobuyasu S, Kae K, Tatsuya Y, Takashi Y, Yoshiyasu $\mathrm{N}$, et al. Expression of enhancer of zeste homolog 2 correlates with survival outcome in patients with metastatic breast cancer: exploratory study using primary and paired metastatic lesions. BMC Cancer. 2017;17:160. doi: 10.1186/s12885-017-3154-3

8. Min D, Xin-Juan F, Zhan-Hong C, Tian-Tian W, Xing L, Jie C, et al. Aberrant expression of enhancer of zeste homologue 2, correlated with HIF-1a, refines relapse risk and predicts poor outcome for breast cancer. Oncol Rep. 2014;32:1101-1107. doi: 10.3892/or.2014.3322

9. Umberto Veronesi Aron Goldhirsch Editors-in-Chief Paolo Veronesi Oreste Davide Gentilini Maria Cristina Leonardi Editors; Breast Cancer, ISBN 978-3-319-48846-2 ISBN 978-3319-48848-6 (eBook) doi: 10.1007/978-3-319-48848-6 Library of Congress Control Number: 2017945756? Springer International Publishing AG 2017, page 43.

10. Xu H, Yu S, Yuan X, Xiong J, Kuang D, Pestell GR, et al. DACH1 suppresses breast cancer as a negative regulator of CD44. Sci Rep. 2017;7:4361. doi: 10.1038/s41598-017-04709-2
11. Tsai J, Bertoni D, Hernandez-Boussard T, Telli ML, Wapnir IL. Lymph node ratio analysis after neoadjuvant chemotherapy is prognostic in hormone receptor-positive and triple-negative breast cancer. Ann Surg Oncol. 2016;23:3310-3316. doi: 10.1245/ s10434-016-5319-8

12. Wasuthit $\mathrm{Y}$, Kongdan $\mathrm{Y}$, Suvikapakornkul R, Lertsithichai P, Chirappapha P. Predictive factors of axillary lymph node metastasis in breast cancer. J Med Assoc Thai. 2011;94(1):65-70.

13. Bachmann IM, Halvorsen OJ, Collett K, Stefansson IM, Straume $\mathrm{O}$, Haukaas SA, et al. EZH2 expression is associated with high proliferation rate and aggressive tumor subgroups in cutaneous melanoma and cancers of the endometrium, prostate, and breast. J Clin Oncol. 2006;24(2):268-273. doi: 10.1200/JCO.2005.01.5180

14. Jene-Sanz A, Váraljai R, Vilkova VA, Khramtsova FG, Khramtsov IA, Olopade IO, et al. Expression of polycomb targets predicts breast cancer prognosis. Mol Cell Biol. 2013;33(19):3951-3961. doi: 10.1128/MCB.00426-13

15. Gonzalez ME, Li X, Toy K, DuPrie M, Ventura AC, Banerjee $\mathrm{M}$, et al. Downregulation of EZH2 decreases growth of estrogen receptor-negative invasive breast carcinoma and requires BRCA1. Oncogene. 2009;28(6):843-853. doi: 10.1038/ onc. 2008.433

16. Si-Hyong J, Jong Eun L, Mee-Hye O, Ji-Hye L, Hyun Deuk C, Kyung$\mathrm{Ju} \mathrm{K}$, et al. High EZH2 protein expression is associated with poor overall survival in patients with luminal A breast cancer. J Breast Cancer. 2016;19(1):53-60. doi: 10.4048/jbc.2016.19.1.53

17. Reijm EA, Timmermans AM, Look MP, Meijer-vanGelder ME, Stobbe CK, van Deurzen CHM, et al. High protein expression of EZH2 is related to unfavorable outcome to tamoxifenin metastatic breast cancer. Ann Oncol. 2014;25:2185-2190. doi: 10.1093/annonc/mdu391

18. Kleer CG, Cao Q, Varambally S, Shen R, Ota I, Tomlins SA, et al. EZH2 is a marker of aggressive breast cancer and promotes neoplastic transformation of breast epithelial cells. Proc Natl Acad Sci U S A, 2003;100(20):11606-10611. doi: 10.1073/ pnas.1933744100

19. Croker AK, Goodale D, Chu J, Postenka C, Hedley BD, Hess DA, et al. High aldehyde dehydrogenase and expression of cancer stem cell markers selects for breast cancer cells with enhanced malignant and metastatic ability. J Cell Mol Med. 2009;13(8B):2236-2252. doi: 10.1111/j.1582-4934.2008.00455.x

20. Yomtoubian S, Lee BS, Verma A, Izzo F, Markowitz G, Choi H, et al. Inhibition of EZH2 catalytic activity selectively targets a metastatic subpopulation in triple-negative breast cancer. Cell Reports. 2020;30:755-770. doi: 10.1016/j.celrep.2019.12.056

21. Tonellotto F, Bergmann A, Abrahão SK, Aguiar SS, Bello AM, Thuler LCS. Impact of number of positive lymph nodes and lymph node ratio on survival of women with node-positive breast cancer. Eur J Breast Health. 2019;15(2):76-84. doi: 10.5152/ ejbh.2019.4414

22. Horiguchi K, Toi M, Horiguchi S, Sugimoto M, Naito Y, Hayashi $Y$, et al. Predictive value of CD24 and CD44 for neoadjuvant chemotherapy response and prognosis in primary breast cancer patients. J Med Dent Sci. 2010;57:165175.

\section{Authors' Contribution:}

MD conceived, designed and did statistical analysis \& editing of manuscript and is responsible for integrity of research.

MD, AK, LjV did data collection and manuscript writing.

MM did review and final approval of manuscript. 